\title{
Basic Operations on Vedic Mathematics: A Study on Special Parts
}

\author{
Krishna Kanta Parajuli \\ Department of Mathematics, Valmeeki Campus, Nepal Sanskrit University
}

Email: kknmparajuli@gmail.com

\begin{abstract}
Vedic Mathematics was rediscovered and reconstructed by Sri Bharati Krishna Tirthaji from ancient Sanskrit texts Veda early last century between 1911 - 1918 is popularly known today is Vedic Mathematics. It is an extremely refined, independent and efficient mathematical system based on his 16 formulae and some sub-formulae with simple rules and principles.

The main purpose of this paper is to communicate a new approach to Mathematics, offering simple, direct, one-line, mental solutions to mathematical problems. In the way of basic mathematical operations like addition, subtraction, multiplication and division can be done in simple ways, and results are obtained quickly and can be checked in a minute by using the Vedic techniques. In this system, for any problem, there is always one general technique and also some special pattern problems. This paper especially concentrates only on the specific pattern of elementary operation of Vedic Mathematics.
\end{abstract}

Keywords: Vedic Mathematics, Ekadhikena Purvena, Nikhilam Navatascharam Dasatah, Urdhvatiryagbhyam, Antyayordashkepi.

\section{Introduction}

The most common meaning of Veda is knowledge [3]. It is considered as the oldest layer of Sanskrit literature and the oldest scriptures of Hinduism. The Vedas are considered divine in origin and are assumed to be direct revelations from God [7]. There are four Vedas: Rigveda, Yajurveda, Samaveda and Atharvaveda [2]. The Vedas are ancient writings whose date is disputed but which date from at least several centuries of B.C. The content of the Vedas was known long before writing was invented and was freely available to everyone. It was passed on by word of mouth. The writings called the Vedas to consist of a huge number of documents (there are said to be millions of such documents, many of which have not yet been translated) and these have recently been shown to be highly structured, both within themselves and concerning each other [2].

Bharati Krishna Tirthaji spent eight years between 1911 - 1918 at the Shringari forest near Shringari Moth for the practice of Brahma-Sadhana to study the advanced Vedanta Philosophy [10]. According to him, the rediscovery and reconstruction of Vedic Mathematics were one of the outputs of his devotion from stray references within the appendix portions of the Atharvaveda. Vedic Mathematics is a system of reasoning and mathematical working based on 16 formulas and 13 sub-formulas with simple rules and principles. Vedic mathematical techniques are also based on the ancient mathematical system as well as the modern system. Each formula provides a principle of mental working applicable to many diverse areas of Mathematics [10].

The most significant quality of Vedic Mathematics is its consistency. It sharpens the mind, improve memory power with concentration, speed up mathematical calculations, minimize careless mistakes and encourage innovations [12]. The beautiful coherence between arithmetic and algebra is visible in the Vedic system. The real beauty and effectiveness of Vedic Mathematics cannot be fully appreciated without actually practicing the system [14]. It will be benefitted from these wonderful, logical, and systematic and faster methods of 
solving the most complex sums. It helps the students to remember that many big digit calculations can be done much faster by Vedic methods than the calculator [5].

After going through the content presented in this paper, serious mathematical issues, higher-level mathematical problems are not taken up in this paper, even though many aspects like four fundamental operations: addition, subtraction, multiplication and division are operated with. In Vedic Mathematics, there are two types of techniques: Specific and general. Those techniques which are fast and effective but can be applied only to a particular combination of numbers are called specific and those which have a much wider scope of application than specific as they deal with a wider range of numbers are general. Mathematical calculations can be done much faster by Vedic methods than by calculators when we use the specific methods. So, this article is concentrated only on the tiny glimpse of elementary operations on mathematics by specific techniques of Vedic Mathematics.

\section{Basic Operations on Vedic Mathematics}

In Sanskrit, the terms sutra means 'Thread of Knowledge'. Vedic Mathematics consists of 16 sutras and a similar number of sub-sutras. Only some of these formulae are used in the basic operation of arithmetic. The meaning of these used sutras in this article is tabulated below [6], [9], [10].

\begin{tabular}{|l|l|}
\hline \multicolumn{1}{|c|}{ Vedic Sutras (Formulae) } & \multicolumn{1}{c|}{ Meanings } \\
\hline Ekadhikeana Purvena (एकाधिकेन पूर्वेण) & By one more than the previous one \\
\hline $\begin{array}{l}\text { Nikhilam Navatascaramam dasatah } \\
\text { (निखिलं नवतश्चरमं दशतः) }\end{array}$ & All from nine and last from ten \\
\hline Urdhvatiryagbhyam (उर्व्वतिर्यगभ्याम,) & Vertically and crosswise \\
\hline Sankalana-Vyavakalanabhyam (संकलनब्यावकलनाभ्याम) & By addition and subtraction \\
\hline Puranapuranabhyam (पूरणा पूरणाभ्याम) & By completion and non-completion \\
\hline Paravartya Yojaayet (परावर्त योजयेत) & Transpose and apply \\
\hline Ekanyunena Purvena (एकन्यूनेन पूर्वेण) & By one less than the previous one \\
\hline Antyayordashkepi (अन्त्ययोर्दशके sपि ) & $\begin{array}{l}\text { The total of the last digit is ten and the previous } \\
\text { part is the same }\end{array}$ \\
\hline Antyayoshatakepi (अन्त्ययोशतकेडपि) & $\begin{array}{l}\text { The total of the last digit is a hundred and the } \\
\text { previous part is the same }\end{array}$ \\
\hline Vamanlyayoh Dashakepi (वामनल्यायोह दशक्रपि) & $\begin{array}{l}\text { The total of the last digit is ten and the previous } \\
\text { part is the same }\end{array}$ \\
\hline $\begin{array}{l}\text { Vamanlyayoh Dashake Gunijah Api (वामनल्यायोहsशक } \\
\text { :गुणिज:डपि) }\end{array}$ & $\begin{array}{l}\text { The total of left two digits is a multiple of ten } \\
\text { and the unit digit is the same }\end{array}$ \\
\hline
\end{tabular}

\subsection{Addition}

The formula used for addition in Vedic Mathematics is Puranapuranabhyam, SankalanaVyavakalanabhyam and Ekadhikeana Purvena. The whole procedure of adding can be summarized in the following steps [8], [9]:

Add the digits column-wise and when the running total becomes greater than 10, put a dot or tick on that number. Move ahead with the excess of 10 and add it to the next digit of the column. Lastly, count the number of dots or ticks and add it to the next column.

$$
\begin{aligned}
& \text { Examples: } \quad 9^{\prime} 8^{\prime} 7 \quad 4200 \\
& 46^{\prime} 6^{\prime} \quad 0 \quad 09^{\prime} 8^{\prime} \\
& 8^{\prime} 47^{\prime} \quad 8^{\prime} 7^{\prime} 6^{\prime} 5^{\prime} \\
& \begin{array}{l}
+248 \\
\hline 2548
\end{array} \quad \begin{array}{l}
+5789 \\
\hline 18852 \\
\hline
\end{array}
\end{aligned}
$$




\subsection{Subtraction}

For the subtraction process, we use the Vedic formula Nikhilam Navatascaramam dasatah. The meaning of this formula is 'All from nine and the last from ten'. This method works faster when subtraction is done from a multiple of 10 i.e. $10,100,1000,10000, \ldots$. .While calculating is adopted by the conventional method, several carry-overs are needed, which wastes time and confusion about accuracy remains, the Vedic method helps us in this regard and saves our precious time [4], [13]. The concepts can be illustrated by taking examples as following:

- $\quad$ Start moving from right to left. Replace every zero from the left with a 9 and the last zero with a 10. The extreme left digit before zero will get reduced by 1 [8], [9].

For example, for subtracting 5472 from 400000

$\begin{array}{rr}400000 & 399910 \\ -5472 & \text { will become }\end{array} \quad \begin{array}{r}-5472 \\ \hline\end{array}$

- When the digit at minuend (upper digit) $>$ Subtrahend digit (lower digit), normal subtraction is done.

- In case the upper digit < lower digit, we take the complement of the difference (i.e. complement of 0 is 10. Complement of 1 is 9 , the complement of 2 is 8 and so on). The complement of the last digit is taken from 10 and the complements of the rest of the digits are taken from 9.

- When we arrive at a stage where there is no need to take the complement, subtract 1 extra from that column.

For example, to subtract, 89543 - 40597, we write

$$
\begin{array}{rrrrr}
8 & 9 & 5 & 4 & 3 \\
-4 & 0 & 5 & 9 & 7 \\
\hline 4 & 8 & 9 & 4 & 6
\end{array} \quad \downarrow \text { from } 10
$$

\subsection{Multiplication}

For multiplication, we can use eight Vedic formulae Antyayordashkepi,, Nikhilam Navatascharam Dasatah, Anurupyena, Ekanyunena Purvena, Antyayoshatakepi, Vamanlyayoh Dashakepi, Vamanlyayoh Dashake Gunijah Api, Urdhvatiryagbhyam [9] [10].

Except for the last formula Urdhvatiryagbhyam, all are the specific formula of multiplication, which has limited application. Many special formulae help us to find the answer to a special type of multiplication even in seconds and the Urdhvatiryagbhyam method helps us to encounter all types of multiplication. The special types of formulae are:

\subsubsection{Antyayotdashakepi}

This formula has limited application and is valid as long as the sum of the unit digit at multiplicand and multiplier is 10 and the remaining digits are the same. The final product will consist of two parts LHS and RHS [10], [12].

Multiply the unit digits and write it in the RHS part. In the LHS part, write the product of (Remaining digit at Ten's/hundred place $) \times($ Remaining digit at Ten's/hundred place +1$)$.

For example, to multiply 75 by $75, \quad$ RHS $=5 \times 5=25$ and LHS $=7 \times(7+1)=72$ (by using the formula Ekadhikena Purvena). So, result $=7225$.

\subsubsection{Vamanlyayoh Dashakepi}

This formula is applicable when the sum of digits placed at the ten's place in the multiplicand and multiplier is 10 and the unit digit of both multiplicand and multiplier is the same. For method, see, [8], [1].

The answer to such questions consists of two parts. 
LHS $=$ Product of two left digits whose sum is $10+$ unit digit; and RHS $=$ Square of the unit digit. For example, to multiply 98 by 18 , LHS $=9 \times 1+8=17$ and RHS $=8 \times 8=64$. The result $=1764$.

\subsubsection{Nikhilam Navatascharam Dasatah}

This formula works better when both the multiplicand and multiplier are very close to the base. The base should be in the form of $10^{\mathrm{n}}$, where $n$ is a natural number. The ideas can be illustrated in stepwise as below [10].

- Write the two numbers one below the other and write the deviations of the two numbers from the base.

- There are two parts

(a) the left-hand part will be obtained by cross operation of two numbers written diagonally.

(b) the right side of the answer will be obtained by multiplying the deviations.

- The number of digits in the right-hand part will be in accordance with the number of zeros in the base number.

Under this formula, there are many cases

(i) When both the numbers are above the base:

For examples, the multiplication of 104 by 103 and 16 by 12 are expressed as:

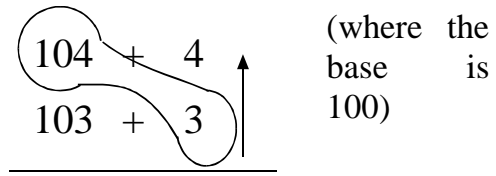

$107 / 12$

$$
\text { So, result }=10712
$$

(ii) When both the numbers are below the base

For example, to multiply 97 by 98 , it is expressed as

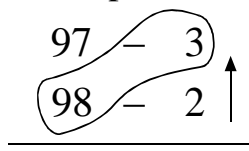

$95 / 06$

(where the base is 100)

So, $\quad$ result $=9506$

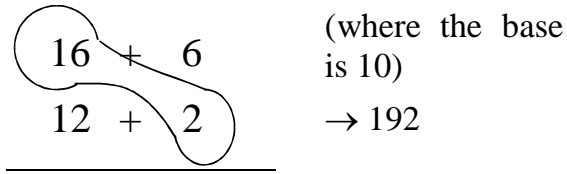

$18 / 12$

$$
\text { So, result }=192
$$

(iii) When one number is above the base and another is less than the base.

To multiply 15 by 9 , it can be expressed as:

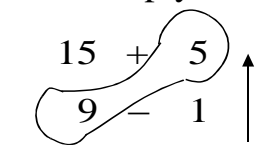

$14 /-5$

$14 / 10-5 \rightarrow 13 / 5$ (where the base is 10 )

So, result $=135$. It is noted that when there is a $(-)$ sign at the right-hand side, we use the Nikhilam formula i.e. subtracting the right-hand digit $(-5)$ from 10 and the left-hand part will get diminished by 1 .

\subsubsection{Ekanyunena Purvena [9], [10]}

The meaning of the Formula is "By one less than the previous one". This formula is used when the multiplier is 9 or 99 or 999 or 9999 etc. The method is divided into two cases

(i) When the number of digits in the multiplicand is equal or less to the number of nines:

The method is as: Subtract 1 from the multiplicand and write the result in LHS and subtract the multiplicand by applying the Nikhilam formula and write the result in RHS.

For example, to multiply 3785 by 999999 , we have

LHS $=3785-1=3784, \quad$ RHS $=999999-3784=996215, \quad$ Result $=3784996215$. 
(ii) When the number of digits in the multiplicand is higher than the number of nines:

It is a little different from (i). To get the result, we have to

- Add as many zero as the numbers of nines to the multiplicand.

- Subtract the original multiplicand from the figure obtained in the $1^{\text {st }}$ step.

For example, to multiply 23758 by 999 , there are 3 nines, so for this, subtracting original multiplicand: $23758000-23758=23734242$.

In the above discussion of case (ii), the formula Ekanyunena Purvena is not seen in use, but can also be used.

\subsection{Division}

In division operation, we shall deal with three Vedic formulae: Nikhilam, Paravartya Yojaayet and Urdhvatiryagbhyam [10]. Here, Nikhilam and Paravartya Yojaayet are specific rules whereas Urdhvatiryagbhyam is a general rule which is also known as the Dhwajanka method of division and is based on the long-established Vedic process of mathematical calculations [10], [12].

In the Nikhilam formula, it has limited application and is useful when every digit of the divisor is greater than 5. The best part of this formula is that there is no subtraction process to be carried out at all [1], [9].

Paravartya Yojaayet formula is Transpose and Apply, which is slightly different from the Nikhilam formula. Paravartya Yojaayet formula works effectively when the first digit of the divisor is 1 . In the Paravartya formula, the complement obtained from the Nikhilam formula will be revised by changing the sign separately. For example, if the divisor is 86 , the nearest base $=100$ and complement $=100-86=14$ and revised complement $=-1-4$.

For the Nikhilam method, the working rules are [8], [9], [10].

- Take a base (in the power of 10) nearest to the divisor and write its complement below the original divisor.

- Separate the extreme right digit of the divided by drawing a slash equal to the number of digits in the divisor. This block is known as the remainder block and the left block is known as the quotient block.

- The number of digits to be placed in the remainder column should be equal to the number of zeros in the base.

- Carry down the first digit of the divisor, which will be the first digit of the quotient, multiply this quotient by the complement and place it in the dividend column; next to the first digit of the dividend.

- Write mechanically the sum of the digits of the $2^{\text {nd }}$ column to get the $2^{\text {nd }}$ digit of the quotient.

- Repeat the process until we get a number in the remainder column. If the remainder is greater than the divisor, continue the same process in the remainder block until the digit in the remainder column is less than that of the original divisor.

For example, to divide 1221340 by 8987 ,

\begin{tabular}{|c|c|c|}
\hline Divisor Column & Quotient Column & Remainder Column \\
\hline \multirow{5}{*}{$\begin{array}{c}8987 \\
\text { Complement }=1013\end{array}$} & 122 & 13340 \\
\hline & 10 & 13 \\
\hline & & $\begin{array}{lll}0 & 39\end{array}$ \\
\hline & $\downarrow \downarrow \downarrow$ & 5065 \\
\hline & 135 & $\begin{array}{llll}8 & 0 & 9 & 5\end{array}$ \\
\hline
\end{tabular}

Here, quotient $=135$ and remainder $=8095$.

\section{Findings}

The documents for the special parts of basic operation on Vedic Mathematics may not be sufficient for the reader. But the presented documents and its representative examples are clear enough to obtain some 
findings with its techniques. There is a contrast between Vedic and Conventional Methods for calculating basic operations. Vedic Mathematics itself is the easiest, enjoyable and one-line mental form of mathematics and some of the calculations are faster than the calculator. Modern methods have just one way of doing, say, division and this is so cumbrous and tedious that the students are now encouraged to use a calculating device whereas the Vedic method can be done without devices. While calculating is adopted by the conventional method, several carry-overs in subtractions, large multiplication tables in multiplications and many hits and trial methods are needed, which wastes time and confusion about accuracy remains, the Vedic method helps us in this regard and saves our precious time.

\section{Conclusion}

Vedic Mathematics is considered as mental Mathematics. It develops accuracy, exactness and precision. The real beauty and effectiveness of Vedic Mathematics cannot be fully appreciated without actually practicing the system. Hence the methods discussed, and organization of the content of the paper shows the basic operation of Vedic Mathematics is an extremely refined and efficient mathematical system. The technique involved in basic operations of Vedic Mathematics is highly efficient, and certainly needs an explanatory approach for further development. This article hence is an explanatory approach for the basic mathematical operations using Vedic Mathematics; its special parts. So, a stepwise, procedural and algorithmic framework of Vedic Mathematics in basic operations can be drawn from this article.

\section{Suggestions and Implications}

With the knowledge of Vedic Mathematics at primary level classes, mathematics would become a favorite subject of all, as they would be able to perform calculations accurately with speedily. To realize this objective, the assimilation of Vedic Mathematics should be given prime importance. The methods and principles can be integrated into an existing school curriculum. The incorporation of Vedic Mathematics into the present issue-based approach makes the system both conceptual and calculation based. Both Vedic Mathematics and Conventional Mathematics give the same result on calculation. Students should be trained on both methods and they should be given to choosing between the methods which they find convenient.

\section{References}

[1] Chauthaiwala S. and Kolluru R. (2010) Enjoy Vedic Mathematics: The art of living international Centre, Bangalore

[2] Flood G.(1996). An Introduction to Hinduism, Cambridge University Press, 35-39.

[3] Ghose S. (2011). Religious Developments in Ancient India, Ancient History Encyclopedia.

[4] Glover J. (2002).Vedic Mathematics today, Online journal of Vedic Mathematics.

[5] Glover J., (2014).The Psychology of Vedic Mathematics, Online International Journal of Vedic Mathematics(Article No. 19). Available: www.vedicmaths.org.

[6] Kansara N. M. (2000). Vedic source of Vedic Mathematics, Indian Journal: Sambodhi, Vol. XXIII.

[7] Kaushal N. and Mishra S. (2017). Management Practices in the Ancient Vedas," Global Journal of Management and Business Research, 17(2).

[8] Singhal V. (2014). Vedic Mathematics for all ages, New Delhi: Motilal Banarassidass.

[9] Thakur R. K. (2013). The Essentials of Vedic Mathematics, New Delhi: Rupa Publication, India.

[10] Tirthaji B. K. (2015). Vedic Mathematics, V. S. Agrawal, Ed, New Delhi: Motilal Banarasidass Pvt. ltd.

[11] Williams K. (2003). The system of Vedic Mathematics - a comparision., Available: www.vedicmaths.org.

[12] William K. (2009). The Natural Calculator, Scotland, UK: Inspiration books.

[13] Williams K. (2010). Discover Vedic Mathematics, Scotland, UK: Inspiration Books. 